\title{
Spatiotemporal Dynamics of Ice Streams Due to a Triple-Valued Sliding Law
}

\section{Citation}

Sayag, Roiy, and Eli Tziperman. 2009. Spatiotemporal dynamics of ice streams due to a triple valued sliding law. Journal of Fluid Mechanics 640: 483-505.

\section{Published Version}

doi:10.1017/S0022112009991406

\section{Permanent link}

http://nrs.harvard.edu/urn-3:HUL.InstRepos:3445991

\section{Terms of Use}

This article was downloaded from Harvard University's DASH repository, and is made available under the terms and conditions applicable to Other Posted Material, as set forth at http:// nrs.harvard.edu/urn-3:HUL.InstRepos:dash.current.terms-of-use\#LAA

\section{Share Your Story}

The Harvard community has made this article openly available.

Please share how this access benefits you. Submit a story.

Accessibility 


\title{
Spatiotemporal dynamics of ice streams due to a triple-valued sliding law
}

\author{
ROIY SAYAG ${ }^{1} \dagger$ AND ELI TZIPERMAN ${ }^{1,2}$ \\ ${ }^{1}$ Department of Earth and Planetary Sciences, Harvard University, Cambridge, MA 02138, USA \\ ${ }^{2}$ School of Engineering and Applied Sciences, Harvard University, Cambridge, MA 02138, USA
}

(Received 10 September 2008; revised 1 August 2009; accepted 3 August 2009)

We show that a triple-valued sliding law can be heuristically motivated by the transverse spatial structure of an ice-stream velocity field using a simple onedimensional model. We then demonstrate that such a sliding law can lead to some interesting stream-like patterns and time-oscillatory solutions. We find a generation of rapid stream-like solutions within a slow ice-sheet flow, separated by narrow internal boundary layers (shear margins), and analyse numerical simulations in two horizontal dimensions over a homogeneous bed and including longitudinal shear stresses. Different qualitative behaviours are obtained by changing a single physical parameter, a mass source magnitude, leading to changes from a slow creeping flow to a relaxation oscillation of the stream pattern, and to steady ice-stream-like solution. We show that the adjustment of the ice-flow shear margins to changes in the driving stress in the one-dimensional approximation is governed by a form of the GinzburgLandau equation and use stability analysis to understand this adjustment. In the model analysed here, the width scale of the stream is not set spontaneously by the ice flow dynamics, but rather, it is related to the mass source intensity and spatial distribution.

Key words: ice sheets, instability, low-Reynolds-number flows

\section{Introduction}

The Siple coast ice streams in Antarctica are bands of fast flowing ice that extend over hundreds of kilometres, whose width is of the order of $20-50 \mathrm{~km}$. Their typical velocity is hundreds to thousands metres per year compared to the metres per year speed of the surrounding ice-sheet flow, and their trajectory is not necessarily dictated by bed topography. The rapid ice-stream flow is typically separated from the slow ice-sheet flow by narrow shear margins, and the ice-stream flow seems distinguished from the ice-sheet flow by being melted at the base. The streams flow over lubricated bed (basal stresses of $\sim 1-10 \mathrm{kPa}$ ), and their width, velocity and path vary on time scales from diurnal (Bindschadler et al. 2003) to centuries or more (Stephenson \& Bindschadler 1988; Retzlaff \& Bentley 1993).

The formation mechanism and characteristics of these ice streams are still not well understood. There are indications that both longitudinal stresses along the side shear margins, and traction at the base are important to ice-stream dynamics (MacAyeal, Bindschadler \& Scambos 1995; Price et al. 2002; Joughin, MacAyeal \& Tulaczyk 2004; Stokes et al. 2007) and therefore to the specific objectives of this paper. We proceed to describe some previous ideas relating to these two factors.

$\dagger$ Email address for correspondence: sayag@fas.harvard.edu 
Because of their importance in the force balance of developed ice streams, one wonders if the weakening of the longitudinal stresses due to shear thinning may be responsible for the instability leading to the formation of streams. Stability studies (Hindmarsh 2006; Sayag \& Tziperman 2008) indicated that spontaneous stream pattern formation due to viscous effects may be less likely, and they may, in fact, stabilize the flow (Balmforth, Craster \& Toniolo 2003; Hindmarsh 2006; Sayag \& Tziperman 2008), except perhaps upstream near the ice-stream onset zones (Price et al. 2002).

The traction at the base of the ice can vary significantly due to several factors (Stokes et al. 2007; Rempel 2008; Schoof \& Rempel 2008), and is especially affected by the drainage of subglacial melt water. This drainage may be inefficient and therefore lead to high water pressure beneath the ice (Weertman 1972; Boulton \& Hindmarsh 1987; Kamb 1987; Walder \& Fowler 1994), and consequently to increased lubrication. Alternatively, in an efficient drainage system, the intense channelized water flux leads to low water pressure (Rothlisberger 1972) and hence to an increased basal friction. The drainage system may transition from one form to the other via reorganization and instabilities (Walder 1982), and may lead to ice-stream stagnation (Anandakrishnan \& Alley 1997). There is evidence for drainage systems of both low and high pressure beneath valley glaciers (Fountain 1994), and of high pressure beneath present ice sheets (Kamb \& Engelhardt 1991); however, there is only some suggestive observational evidence for low pressure drainage systems below former ice sheets (Clark \& Walder 1994; Boulton et al. 2007a,b).

The complex response of the bottom shear stress $\tau^{b}$ to the basal ice flow speed $u^{b}$ (where superscript ${ }^{b}$ refers to basal quantities), water availability, the presence of sediments and other factors, is commonly represented through a simplified sliding law such as $u^{b}=f\left(\tau^{b}\right)$ (Weertman 1964, 1979), or $u^{b}=f\left(\tau^{b}, N\right)$, where $N$ is the difference between the ice overburden pressure and the basal water pressure (Lliboutry 1968; Nye 1969, 1970; Kamb 1970; Lliboutry 1979). Multivalued sliding laws in which the velocity is double or triple valued function of the bottom stress (Lliboutry 1968; Fowler 1986; Lliboutry 1987) were supported by different detailed physical mechanisms (Iken 1981; Fowler 1987a; Fowler \& Johnson 1995; Schoof 2005; Gagliardini et al. 2007). Quasi-periodic oscillatory motion of ice referred to as a surge (Raymond 1987) was explained by a triple-valued sliding law, in which bottom stress increases with velocity at high velocities (Lliboutry 1969; Hutter 1982a,b; McMeeking \& Johnson 1986; Fowler 1986, 1987b, 1989; Greenberg \& Shyong 1990; Fowler \& Johnson 1995, 1996; Fowler \& Schiavi 1998). Fowler \& Johnson (1996) also examined the effect of the possible instability in a laterally extensive flow due to a triple-valued sliding law. They found isolated domains of rapid flow in a time-independent problem, and suggested that this indicates a possible development of ice streams.

In this work we show that a triple-valued sliding law can be motivated by the cross-stream flow structure of ice streams, as observed for example in the Siple coast, West Antarctica. We do not a priori specify a particular physics for the basal composition or hydrology. Rather, we use the observation that the horizontal shear of the downstream velocity is much smaller in the stream and inter-stream zones, than in the narrow 'shear margin' between them (Raymond et al. 2001), and apply boundary layer theory, to motivate and analytically obtain a triple-valued functional relationship between the ice basal velocity and the bottom shear stress $\tau^{b}(\S 3)$. Caveats to this approach are further discussed below.

We demonstrate numerically in $\S 4$ that depending on the magnitude of the mass accumulation forcing, this sliding law can account for three modes of flow: (i) slow 


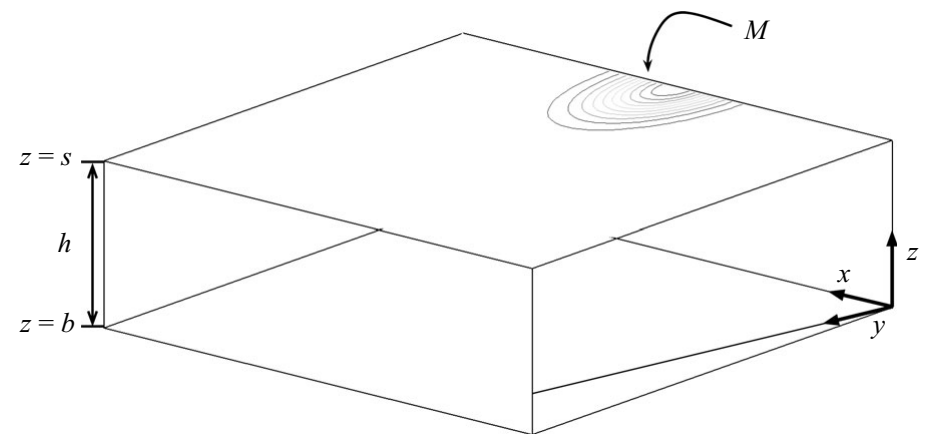

FIGURE 1. Ice-sheet geometry in Cartesian coordinates $(x, y, z)$, corresponding to across-flow, along-flow and upward directions. The contours at $z=s$ mark the spatial distribution of the mass source $M$ discussed in $\S 4$.

ice-sheet-like flow with no stream patterns, (ii) oscillatory surge mode and (iii) an icestream mode. These modes were also seen by Fowler \& Johnson (1996) as a result of their multivalued sliding law. We add to that work by using a model with two rather than just one horizontal flow direction, as well as including explicit two-dimensional momentum equations and longitudinal stresses. We also show that the adjustment of the ice-stream shear margins to changes in the driving stress in the one-dimensional approximation is governed by a form of the Ginzburg-Landau equation and use stability analysis to understand this adjustment. Finally, we discuss how the width scale of an ice stream may be related to the mass source rather than be determined by the inherent physical parameters of the problem.

\section{Model equations and boundary conditions}

Consider a thin, isothermal ice flow within a rectangular domain, over an idealized flat bed with a constant slope (simplifying the bed topography of the Siple coast). The two horizontal directions are $\boldsymbol{x}$ (transverse to the mean flow) and $\boldsymbol{y}$ (along the mean flow), and $z$ is the vertical. The ice surface is located at $z=s(x, y, t)$ and the bed at $z=b(y)$ so that the ice thickness is $h(x, y, t)=s-b$ (figure 1). The ice density is $\rho$ and its velocity is $\boldsymbol{v}=u \boldsymbol{x}+\boldsymbol{v} \boldsymbol{y}$. We assume (i) that the bottom shear stresses at the ice-bed interface are much smaller than the corresponding stresses in the glacier bulk (which implies that velocity vertical shear within the ice may be neglected), (ii) a shallow ice flow and (iii) a free surface. Integrating the Stokes equations over the vertical (MacAyeal 1989) and non-dimensionalizing, we obtain the momentum and mass conservation equations

$$
\begin{gathered}
0=\epsilon\left[2 h\left(2 u_{, x}+v_{, y}\right)\right]_{, x}+\epsilon\left[h\left(u_{, y}+v_{, x}\right)\right]_{, y}-\phi h(h+b)_{, x}-\tau_{x}^{b}, \\
0=\epsilon\left[h\left(u_{, y}+v_{, x}\right)\right]_{, x}+\epsilon\left[2 h\left(u_{, x}+2 v_{, y}\right)\right]_{, y}-\phi h(h+b)_{, y}-\tau_{y}^{b}, \\
h_{, t}=\eta M-\psi\left[(u h)_{, x}+(v h)_{, y}\right],
\end{gathered}
$$

where the $x$ derivative of $v$, for example, is denoted $v_{, x}$ and the notation is given in table 1. The effective viscosity $\mu$ is assumed constant (Newtonian fluid); the bottom shear stress, $\boldsymbol{\tau}^{b}=\left(\tau_{x}^{b}, \tau_{y}^{b}\right)$, depends on the velocity field and other properties of the ice and the bed, and its constitutive relationship is discussed below in $\S 3.1 ; M=M(x, y)$ is a prescribed net accumulation rate. The nondimensionalization is based on the scales $[h],[\mu],[v],[L],[T],[M]$ and $\left[\tau^{b}\right]$, where $v=v^{\prime}[v], x=x^{\prime}[L], y=y^{\prime}[L], b=b^{\prime}[h], M=M^{\prime}[M], \tau_{y}^{b}=\tau_{y}^{b^{\prime}}\left[\tau^{b}\right]$ and so on, with 


\begin{tabular}{|c|c|}
\hline Symbol & Value (units) \\
\hline $\begin{array}{l}a=-v^{2} \\
b\end{array}$ & \\
\hline $\begin{array}{l}b_{, y} \\
F_{x}, F^{\prime}\end{array}$ & $72 \times 10^{-4}$ \\
\hline $\begin{array}{l}g \\
h\end{array}$ & $9.81 \mathrm{~m} \mathrm{~s}^{-2}$ \\
\hline $\begin{array}{l}{[h]} \\
k\end{array}$ & $1800 \mathrm{~m}$ \\
\hline $\begin{array}{l}{[L]} \\
\mathscr{L}\end{array}$ & $250 \mathrm{~km}$ \\
\hline$m$ & \\
\hline $\begin{array}{l}M, M_{0}, M_{s} \\
r, v\end{array}$ & \\
\hline $\mathscr{R}$ & \\
\hline$s$ & \\
\hline $\begin{array}{l}t,[T] \\
v=(u, v)\end{array}$ & \\
\hline$[v]$ & $1253 \mathrm{~m} \mathrm{yr}^{-1}$ \\
\hline$v_{0}, v_{ \pm}$ & \\
\hline$x, y$ & \\
\hline$\beta$ & $50(\mathrm{~m} / \mathrm{s})^{-1}$ \\
\hline $\begin{array}{l}\epsilon \\
\vartheta\end{array}$ & $1 \times 10^{-3}$ \\
\hline$\mu$ & \\
\hline$[\mu]$ & $10^{14} \mathrm{~Pa} \mathrm{~s}$ \\
\hline$\rho$ & $900 \mathrm{~kg} \mathrm{~m}^{-3}$ \\
\hline$\sigma_{x}, \sigma_{y}$ & $0.1,0.2$ \\
\hline $\boldsymbol{\tau}^{b}=\left(\tau_{x}^{b}, \tau_{y}^{b}\right)$ & \\
\hline $\begin{array}{l}{\left[\tau^{b}\right]=\rho g[h] b_{, y}} \\
{\left[\tau_{d}\right]}\end{array}$ & $114420 \mathrm{~Pa}$ \\
\hline $\begin{array}{l}\phi \\
\operatorname{Re}(\omega)\end{array}$ & 1 \\
\hline
\end{tabular}

Description

Bifurcation parameter in the sliding law

Subglacial bed elevation

Subglacial bed slope

ә $F / \partial x$, dimensionless $F$

Gravitational acceleration

Ice thickness field

Vertical length scale

Transverse wavenumber

Horizontal length scale

Lyaponov functional of the one-dimensional model

Parameter in the sliding law

Ice mass source, its amplitude and its steady state value

Parameters in the postulated velocity solution (3.3)

Reynolds number

Ice surface elevation

Time, time scale

Ice velocity field

Horizontal velocity scale

Homogeneous steady state solutions of the onedimensional problem (3.7)

Horizontal coordinates

Free parameter in the sliding law (4.1)

Longitudinal shear stress gradient scale

Velocity magnitude

Ice effective viscosity

Ice effective viscosity scale

Ice density

Ice mass source distribution parameters

Bottom stress-related coefficient in potential function

Ice bottom shear stresses

Bottom stress scale

Driving stress scale

Scale ratio of driving to bottom stress

Growth rate

TABle 1. Notation.

primes labelling dimensionless variables and then dropped. The four dimensionless numbers above are

$$
\begin{array}{cc}
\epsilon=\frac{[h][v][\mu]}{\left[\tau^{b}\right][L]^{2}}, & \phi=\frac{\left[\tau_{d}\right]}{\left[\tau^{b}\right]}, \\
\eta=\frac{[M][T]}{[h]}, & \psi=\frac{[v][T]}{[L]},
\end{array}
$$

where $\left[\tau_{d}\right]=\rho g[h]^{2} /[L]$ is the scale for the driving stress. Table 1 shows, in addition to the notation, the approximate scales and the consequent values of the dimensionless numbers.

The lateral boundaries (parallel to the mean flow, $x=0,1$ ) are assumed rigid (no normal flow) and frictionless (free slip),

$$
u=0, \quad \tau_{x y}=0, \quad \text { on } x=0,1 .
$$


The domain is finite in $y$, with a rigid boundary at $y=0$ and an outflow boundary at $y=1$, as discussed in $\S 4$.

\section{The triple-valued sliding law and ice-stream stability in a one-dimensional model}

\subsection{Motivating the triple-valued sliding law}

Ice streams are bounded by shear margins, which appear to be internal boundary layers between a slow ice-sheet-like flow and fast stream flow. We consider first a highly idealized one-dimensional simplification of the model, and look for a sliding law that can account for a steady ice-stream-like solution. Assume that the flow is only in the $y$ direction, neglect any variations in $y$ of the flow field and thickness, and assume that the flow is driven due to a constant bottom slope $b_{, y}$, and that the thickness is constant $(h=1)$. Applying these assumptions to (2.1)-(2.3), we find that the only nontrivial equation is

$$
0=\epsilon v_{, x x}-\phi b_{, y}-\tau_{y}^{b} .
$$

The three terms represent the divergence of the longitudinal shear stresses, the bottom slope driving stress and the bottom friction. Given our choice of parameters, $\phi \sim 1$, while $\epsilon \sim 10^{-3}$ (table 1 ), the viscous term is very small compared with the other two terms, unless a solution with an internal boundary layer, where $\left|v_{, x x}\right| \gg 1$, exists. Within such a boundary layers, of width $L \sqrt{\epsilon}$, the viscous term becomes comparable to the other two. Assume now that the bottom stress is a function of the sliding velocity, $\tau_{y}^{b}=\tau_{y}^{b}(v)$ and attempt to find what functional form may be consistent with an ice-stream-like structure.

Some important caveats are due at this point. The observed flat velocity profile within the ice streams (e.g. Raymond et al. 2001) may be at least in part due to the effect of the shear thinning viscosity of ice. This, in contradiction to our above assumptions, does not necessarily imply that the viscous stresses are not an important part of the balance within the ice stream and away from the margins (e.g. Whillans \& van der Veen 1997). In addition, the sliding velocity is very likely to explicitly depend also on multiple factors such as the effective pressure, ice temperature, surface configuration parameters (Schoof 2004a), spatial heterogeneity in bed properties, etc. Bearing these caveats in mind, we proceed to see what lessons may be learned by our possibly unrealistic simplifications.

The dominant balance outside the shear margins (internal boundary layers) is thus,

$$
\tau_{y}^{b}(v)=-\phi b_{, y} .
$$

An ice-stream solution implies both fast and slow flows away from shear margins, one being about two orders of magnitude faster than the other. This implies that $v$ should be a multivalued function of $\tau_{y}^{b}$ with at least two stable solutions of (3.2). We expect the stability of solutions to (3.2) to depend on the sign of the slope $\mathrm{d} \tau_{y}^{b} / \mathrm{d} v$, so that the existence of two stable solutions implies that $v$ has to be a triple-valued function of $\tau_{y}^{b}$, similar to that developed by Fowler (1987b), Fowler \& Johnson (1996) and Fowler \& Schiavi (1998).

We now postulate a solution to $v$ which represents the transition from a slow ice flow to a rapid stream flow, with a shear margin in between,

$$
v(x)=1+v \tanh \left(r\left(x-x_{0}\right)\right),
$$



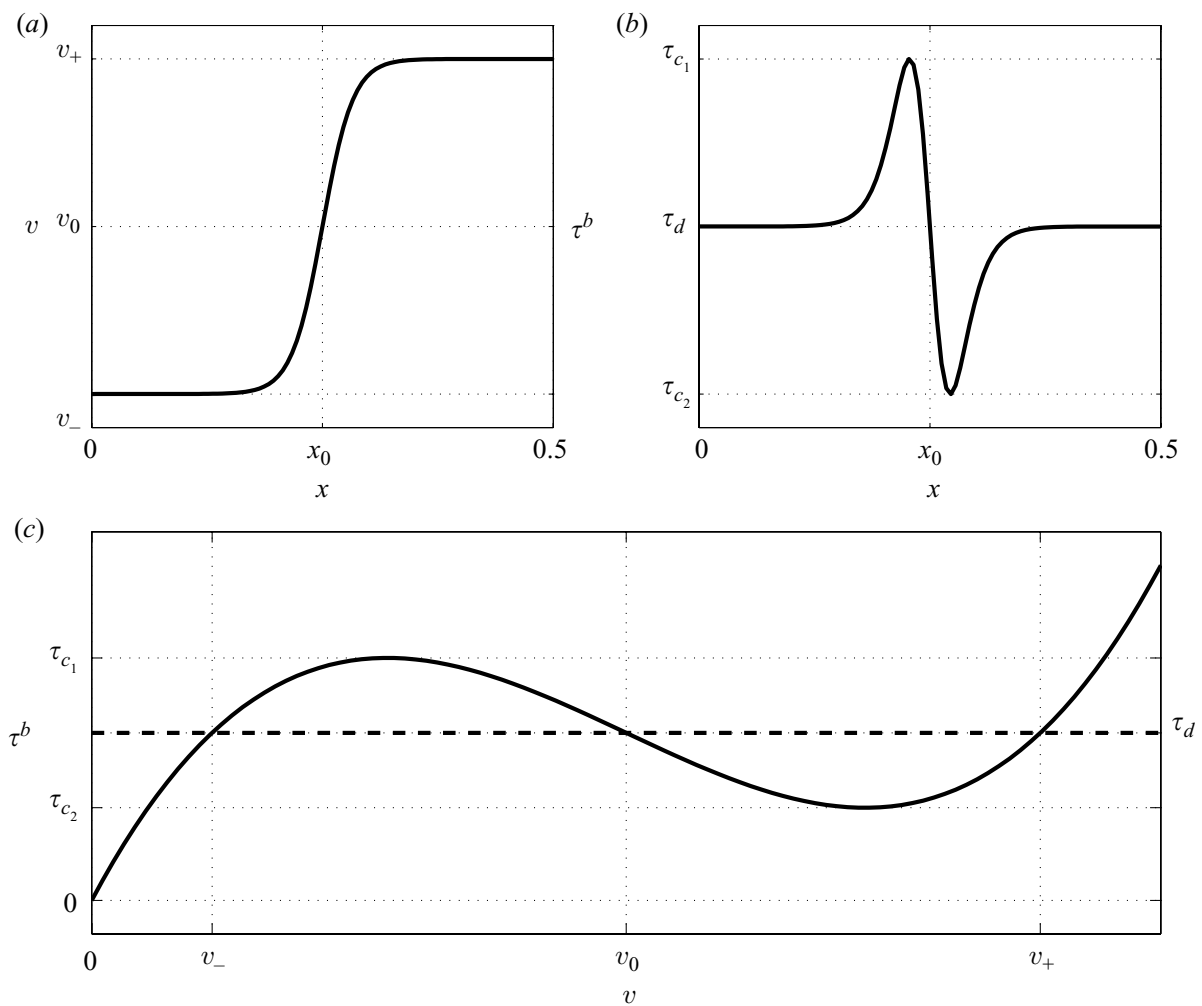

FIGURE 2. The one-dimensional model results with $a=-0.6, r=30$ and $x_{0}=0.25$. ( $a$ ) The $a$ priori postulated downstream velocity $v(x)$, with an internal boundary layer. $x=0.5$ is the centre of an ice stream (only half of which is shown) and the axis of symmetry. (b) The resultant friction law $\tau_{y}^{b}(v)$ and the driving stress, $\tau_{d}$ (dash line). The unstable branch is the part of the curve with a negative slope. (c) The bottom friction spatial distribution $\tau_{y}^{b}(x)$.

where $x, x_{0} \in\left[0, \frac{1}{2}\right]$, and where $0<v \leqslant 1$ and $r$ are parameters. The benefit of using (3.3) is that derivatives of $v$ can be written as a function of $v$. Specifically, $v_{, x x}=(1 / m)\left((v-1)^{3}+a(v-1)\right)$ where $m^{-1}=2(r / v)^{2}$ and $a=-v^{2}$. This results in a cubic friction law which corresponds to a triple-valued sliding law,

$$
\tau_{y}^{b}(v)=\frac{\epsilon}{m}\left((v-1)^{3}+a(v-1)+1+a\right),
$$

The constraint $\tau^{b}(v=0)=0$ results in the relation

$$
\phi b_{, y}=-\frac{\epsilon}{m}(1+a),
$$

which we use to determine the value of $r$.

The prescribed velocity profile and resulting cubic friction law are shown in figure 2 .

\subsection{Stability of the ice-stream shear margins}

The Reynolds number of the flow under consideration is of the order of $10^{-12}$ and therefore the time scale of the flow in the current model is not set by time derivative and inertial terms in the momentum equations, but by that in the conservation of mass equation. However, studying the flow stability while neglecting the explicit time dependence in the momentum equations leads to a singular perturbation problem, and the time derivative in the momentum equation is therefore needed to gain insight 
into the stability of the flow as well as into the adjustment of the shear margin to changes in the driving stress. For this reason, we re-introduce the small time derivative term into (3.1),

$$
\mathscr{R} v_{, t}=\epsilon v_{, x x}-\phi b_{, y}-\tau_{y}^{b},
$$

where $\mathscr{R}=\rho[h][v] /\left[\tau^{b}\right][T] \ll \epsilon$ is the Reynolds number. If the right-hand side is perturbed (e.g. by a small change in the driving stress due to a surface slope in the $y$ direction which would supplement the $\phi b_{, y}$ term), the velocity field, including the location of the shear margin, will adjust accordingly, and this (rapid) adjustment is the focus of the following analysis.

As a result of the triple-valued sliding law, there are three steady and uniform solutions to (3.6) and (3.4),

$$
\bar{v}_{0}=1, \quad \text { and } \quad \bar{v}_{ \pm}=1 \pm \sqrt{-a},
$$

which correspond to the three intersections of the dashed line in figure $2(b)$ with the solid curve. Consider first the stability of these uniform flow solutions. Linearizing (3.6) about one of the above three solutions, denoted $\bar{v}$, we find the equation for a small perturbation $v$,

$$
\mathscr{R} v_{, t}=\epsilon v_{, x x}-\tau_{v} v,
$$

where $\tau_{v}=\left.(\mathrm{d} / \mathrm{d} v) \tau_{y}^{b}\right|_{v=\bar{v}}$. Looking for a solution of the form $v=\mathrm{e}^{\mathrm{i} k x+\omega t}$ we obtain the growth rate,

$$
\omega=-\frac{\epsilon k^{2}+\tau_{v}}{\mathscr{R}} .
$$

This implies that the states $\bar{v}_{ \pm}$, are stable while $\bar{v}_{0}$, where $\mathrm{d} \tau_{y}^{b} / \mathrm{d} v<0$, is unstable. We emphasize that the magnitude of $\omega$ represents only the speed of adjustment of the ice flow, including the location of the shear margin, to changes in the driving stress. Understanding the fuller margin migration problem requires an additional analysis, that is not pursued here, of the time-dependent mass conservation equation or of slower evolving state variables that control the triple valued sliding law.

Consider next the stability of a non-uniform flow with a single shear margin, shown in figure 2(a). Transform to new variables

$$
f=\frac{(v-1)}{\sqrt{|a|}}, \quad t^{\prime}=\frac{\epsilon|a|}{m \mathscr{R}} t, \quad x^{\prime}=\sqrt{\frac{|a|}{m}} x,
$$

which yields, after dropping the primes,

$$
f_{, t}=f-f^{3}-\gamma+f_{, x x}
$$

where $\gamma=\left((1+a)+\frac{m}{\epsilon} \phi b_{, y}\right) /(|a| \sqrt{|a|})$ vanishes here by (3.5), but in the more general case, in the presence of ice thickness gradients, the driving stress in the $y$ direction becomes $-\phi(h+b)_{, y}$, which leads to $\gamma \sim h_{, y} \neq 0$. Equation (3.11) is the time-dependent Ginzburg-Landau equation for the real field, $f$ (e.g. Hagberg \& Meron 1993, 1994), and has three steady uniform solutions $f_{ \pm}, f_{0}$ corresponding to (3.7) for $\gamma=0$. Note that (3.11) is a 'gradient system' given by

$$
\begin{gathered}
f_{, t}=-\delta \mathscr{L} / \delta f \\
\mathscr{L}[f]=\int_{-\infty}^{\infty} \mathrm{d} x\left(E(f)+\frac{1}{2}\left(f_{, x}\right)^{2}\right), \\
E(f)=\frac{1}{4} f^{4}-\frac{1}{2} f^{2}+\gamma f,
\end{gathered}
$$


where $\mathscr{L}[f]$ is the Lyapunov functional of this system. We are assuming an infinite domain here for simplicity. The minima of $E(f)$ and of $\mathscr{L}[f]$ are $f_{ \pm}$, the two uniform steady solutions of (3.11), for which also $f_{, x}=0$. It is easy to show that $\mathrm{d} \mathscr{L} / \mathrm{d} t \leqslant 0$, so that the margin location in the along-stream velocity field $v(x, t)$ as reflected also by the structure of $f(x, t)$ would evolve until $\mathscr{L}[f]$ reaches a minimum.

To evaluate the direction the shear-margin movement due to the adjustment in response to a non-zero perturbation to the driving stress parameter $\gamma$, assume a solution with a shear margin separating between a uniform slow flow and a uniform faster flow, and substitute a travelling wave solution $f(x, t)=f(\xi)=f(x-c t)$, where $c$ is the wave velocity, into (3.11). This solution represents a tanh-like shear margin structure (figure $2 a$ ) moving at a speed $c$. We find from such a substitution that

$$
f^{\prime \prime}+c f^{\prime}+f-f^{3}-\gamma=0,
$$

where primes refer to a derivatives with respect to $\xi$. Multiplying (3.15) by $f^{\prime}$, integrating over the entire domain using $f^{\prime} \rightarrow 0$ as $\xi \rightarrow \pm \infty$, and solving for $c$ we find an explicit expression for the direction of motion of the margin,

$$
c= \begin{cases}\alpha\left(E\left(f_{+}\right)-E\left(f_{-}\right)\right), & \text {if } \lim _{\xi \rightarrow \pm \infty} f=f_{ \pm}, \\ \alpha\left(E\left(f_{-}\right)-E\left(f_{+}\right)\right), & \text {if } \lim _{\xi \rightarrow \pm \infty} f=f_{\mp},\end{cases}
$$

where $\alpha^{-1}=\int_{-\infty}^{\infty} \mathrm{d} \xi f^{\prime 2}>0$.

Applying this analysis to the case of an ice stream bounded by two shear margins, we find that if $\gamma<0$ (e.g. due to a driving stress $h_{, y}$ in the direction of the ice-stream flow) then $E\left(f_{+}\right)<E\left(f_{-}\right)$so that the margins would move away from each other (figure $3 a, d$ ), while if $\gamma>0$ (due to a driving stress $h_{, y}$ opposing the ice-stream flow) the margins would converge towards each other (figure $3 c, f)$. At $\gamma=0, E\left(f_{+}\right)=E\left(f_{-}\right)$ and $c=0$, so that the ice-stream width would remain constant (figure $3 b, e$, see also $\S 3.1$ ). We note again that this calculation only reflects the adjustment of the shear margins to changes in the driving stress as it is reflected in the value of $\gamma$. The magnitude of the velocity $c$ does not represent the shear-margin migration velocity, which may be determined only by analysing the dynamics leading to changes in $\gamma$ as explained above.

\section{Two-dimensional solutions}

Consider a time-dependent flow in a finite domain using the model (2.1)-(2.3), forced by a prescribed mass source $M$. Next, we present simulation results of this two-dimensional model in a domain with an outflow boundary.

\subsection{Sliding law generalization, boundary conditions and numerical model}

We first slightly modify the friction law such that the slow solution is sufficiently slow to represent an ice-sheet-like flow, while maintaining its overall structure consistent with the above cubic friction law,

$$
\boldsymbol{\tau}^{b}=\frac{v}{\vartheta} \frac{\epsilon}{m}\left((\vartheta-1)^{3}+a(\vartheta-1)+1\right) \tanh (\beta \vartheta),
$$

where $\beta$ is a parameter that controls the value of the slower stable velocity solution (figure 4), and $\vartheta=|\boldsymbol{v}|$.

The upstream boundary $(y=0)$ is now assumed rigid (no normal flow) and frictionless (free slip):

$$
v=0, \tau_{x y}=0 \text {, at } y=0 .
$$



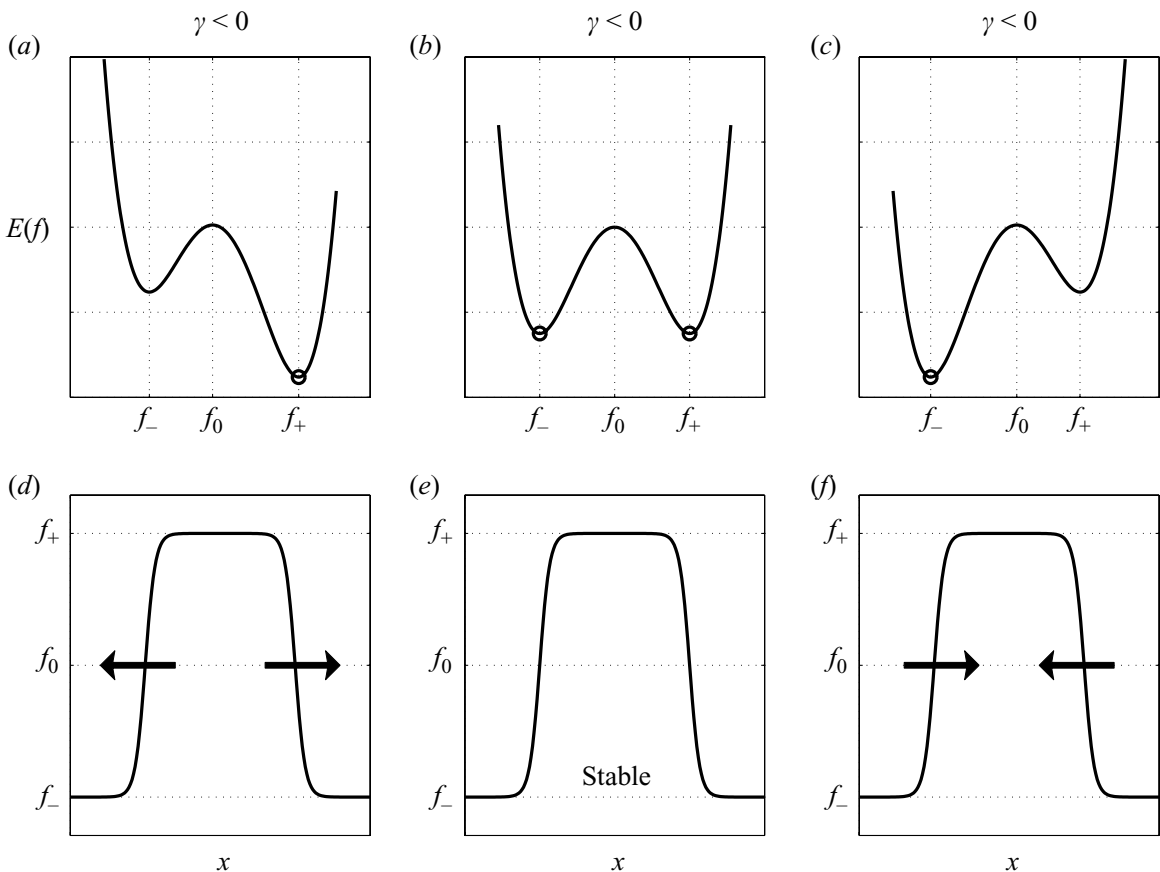

FigurE 3. The evolution of the shear margins as a function of the driving stress parameter $\gamma .(a-c)$ The potential function $E(f)$ for (left to right) $\gamma=-0.1,0$ and 0.1 . The $\circ$ marks the global minimum of $E(f)$ which is the state to which the system evolves. $(d-f)$ The initial downstream velocity along the transverse coordinate, and arrows that mark the direction to which the shear margins travel. At $\gamma=0$ the system is in a minimum of $E(f)$ at both of the steady and uniform states $f_{ \pm}$, and therefore the shear margins remain steady. Note that $f_{ \pm}$ and $f_{0}$ change with $\gamma$.

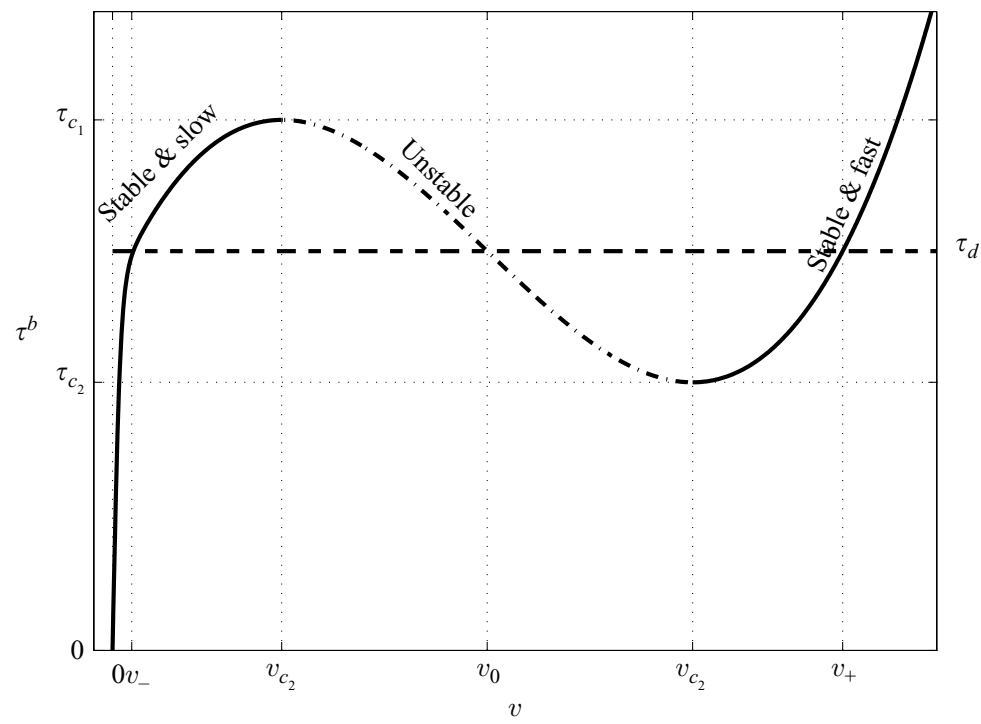

Figure 4. A cross-section of the friction law $\tau(v ; u=0)(4.1)$, with $a=-0.9$ and $\beta=50$, that is used in the two-dimensional simulations in finite domain, and the driving stress scale, $\left[\tau_{d}\right]$ (dash line). This friction law is composed of two stable branches, slow $\left(v<v_{c_{1}}\right)$ and fast $\left(v>v_{c_{2}}\right)$, and an intermediate unstable branch $v_{c_{1}}<v<v_{c_{2}}$. 
A proper choice for a realistic downstream boundary would be a grounding line, the location where the ice becomes shallow enough to start floating over the ocean. For the sake of simplicity, however, we consider another outflow boundary condition (Papanastasiou, Malamataris \& Ellwood 1992) which allows us to truncate the domain arbitrarily, before the grounding line location. Specifically, the only condition specified at the downstream boundary is

$$
v_{, y}=0 \quad \text { at } y=1,
$$

with additional numerical details provided in Appendix B.3.1. Experiments with different downstream boundary conditions (not shown) indicated that the qualitative characteristics of the mechanism we present here are not affected by these specific choices.

We solve (2.1)-(2.3) and (4.1), with the boundary conditions (2.6), (4.2) and (4.3), using a finite difference formulation on the grid shown in figure 9 (Appendix B). The numerical solver is tested against two analytic solutions (Appendix A) and is found to agree with them to a very high degree of accuracy.

Each model simulation is initiated with a steady flow that is independent of $x$, is unidirectional $(u=0)$, of a constant thickness $h$, and where the outflow is balanced by a mass accumulation $M_{s}(y)$ (Appendix A). The experiments below are forced by a mass flux that is the sum of the above flux $M_{s}$, needed to maintain the $x$-independent steady solution, plus a perturbation Gaussian mass source

$$
M(x, y)=M_{0} \exp \left(-\frac{\left(x-x_{0}\right)^{2}}{\sigma_{x}^{2}}-\frac{\left(y-y_{0}\right)^{2}}{\sigma_{y}^{2}}\right),
$$

where $x_{0}=1 / 2, y_{0}=0, \sigma_{x}=0.1, \sigma_{y}=0.2$, and where $M_{0}$ is a constant scalar parameter of dimensions metres per year. The choice of $\sigma_{x}, \sigma_{y}$ and $M_{0}$ is discussed below, in $\S 5$.

\subsection{Solutions}

We now vary the amplitude of the Gaussian mass source (4.4), $M_{0}$, in the range of tens to hundreds of metres per year and find that the flow responds in three regimes: (i) steady flow without ice streams for a weak mass source, (ii) a steady ice-stream mode for a strong mass source and (iii) a relaxation-oscillation mode for intermediate magnitudes of the mass source. $\dagger$

\subsubsection{Weak mass source solutions}

Steady solutions without stream-like patterns exist for mass source magnitudes, $M_{0} \lesssim 50 \mathrm{~m} \mathrm{yr}^{-1}$ (figure 5). The relatively weak source mass influx is dispersed effectively via the slow stable solution of figure 4 . The generated surface slopes are too small to drive the ice flow beyond the critical velocity threshold where an instability would lead to the faster solution. The flow converges to steady state within $\sim 1000$ years (figure $5 a$ ). Note that the large and unrealistic values of the mass accumulation source here, specified over a small area of the domain, are meant to represent smaller accumulation rates over larger upstream areas in reality.

\subsubsection{Strong mass source solutions}

A steady ice-stream-like flow mode exists for relatively large values of the mass source, $M_{0} \gtrsim 150 \mathrm{~m} \mathrm{yr}^{-1}$ (figure 6). Such mass source results in a buildup of steep thickness gradients upstream, at the vicinity of the source. The flow is therefore

$\dagger$ Animations of the flow, in the three regimes are available as a supplement to the online version of this paper. 

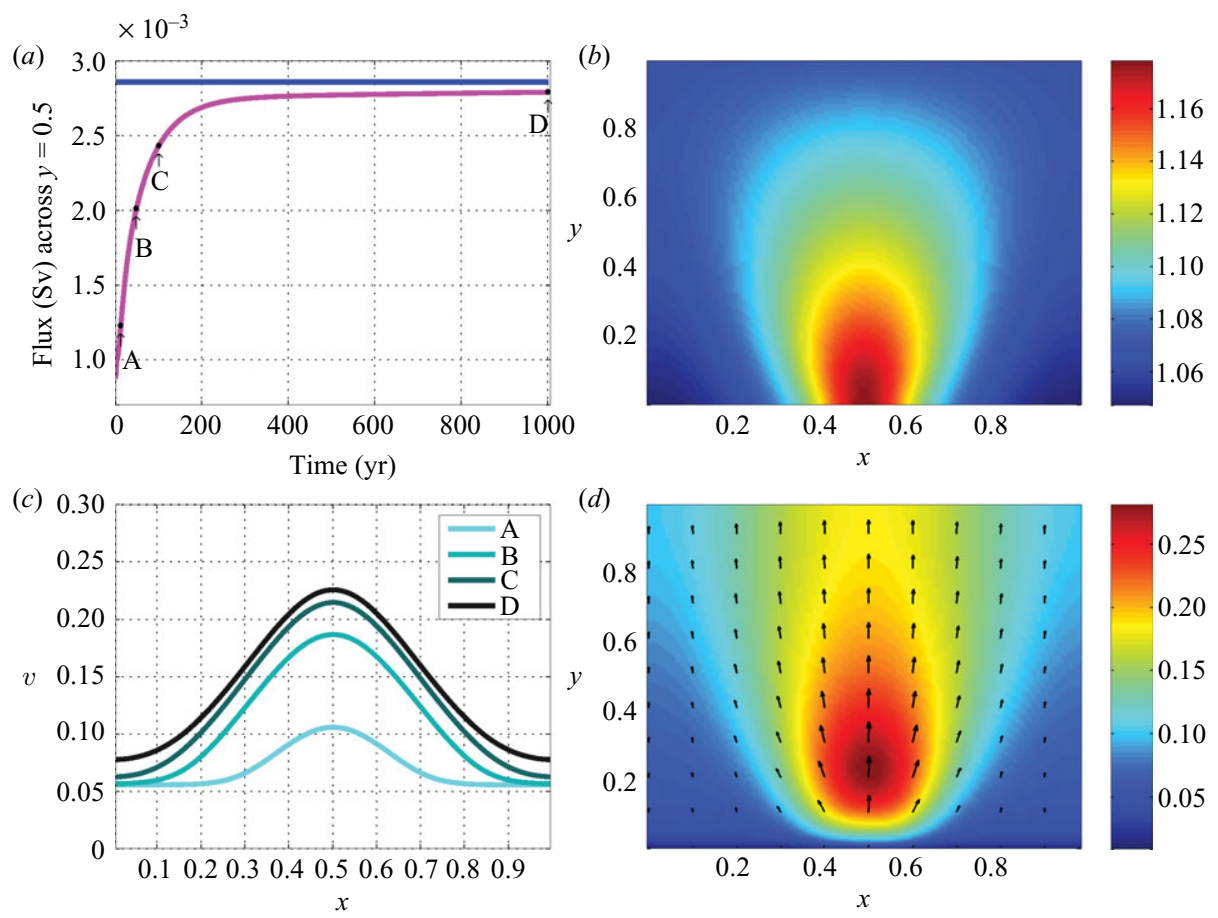

FigurE 5. Diagnostics for the solution forced with relatively weak mass source, $M=30 \mathrm{~m} \mathrm{yr}^{-1}$. (a) The mass flux across $y=0.5$ (magenta) and the source mass influx $M$ (blue). (b) The ice thickness distribution at steady state. (c) The four snapshots of the cross-stream profiles of the downstream velocity, $v(x, y=0.5)$, at the times marked A, B, C, D in $(a)(20,50,100$ and 1000 years, respectively). $(d)$ The velocity field at steady state (D in $(a)$ ). Arrows show the velocity vectors and colours the flow speed.

driven beyond the critical velocity ( $v_{c_{1}}$ in figure 4$)$ at the vicinity of the source, becomes unstable and a transition to the fast stable flow regime (velocity larger than $v_{c_{2}}$ in figure 4) occurs. The mass influx flows away from the area of the mass source via the fast stable velocity mode all the way to the open boundary, with clearly distinguished shear margins (figure $6 c$ ). As the ice stream evolves, the shear margins move away from the its centre, and then back towards the centre (figure $6 c$ ), until they reach a steady position (within 15-20 years, figure $6 a$ ), where the stable and narrow fast-flow region covers only $\sim 20 \%$ of the downstream boundary (figure $6 c, d$ ). In the steady state no significant thickness differences occur between the fast flowing region and the slow one (figure $6 b$ ).

A consequence of the multiple equilibria allowed by the triple-valued sliding law is that at steady state, a slow flow and a flow that is two orders of magnitude faster co-exist at different spatial locations (figure 8). At the same time, there is only a small difference in the bottom stress $\tau_{y}^{b}$ between the fast flow and the slower flow, away from the shear margins (which is a different scenario from a bed that behaves plastically Schoof 2004b).

\subsubsection{Intermediate mass source amplitude, oscillatory solutions}

For intermediate mass source magnitudes, $100 \lesssim M_{0} \lesssim 150 \mathrm{~m} \mathrm{yr}^{-1}$, the flow exhibits a relaxation oscillation (figure 7, similar to what Fowler \& Johnson 1996 called an 'ice-sheet surge'). A cycle begins without a stream pattern (as in the case of the weak mass source), with growing surface slopes due to local mass accumulation near 

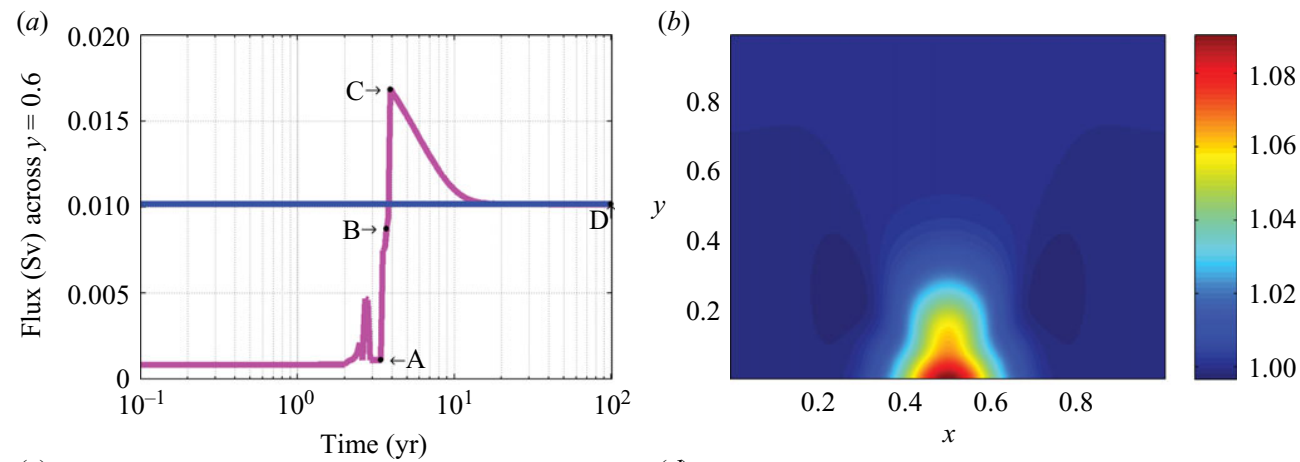

$(c)$
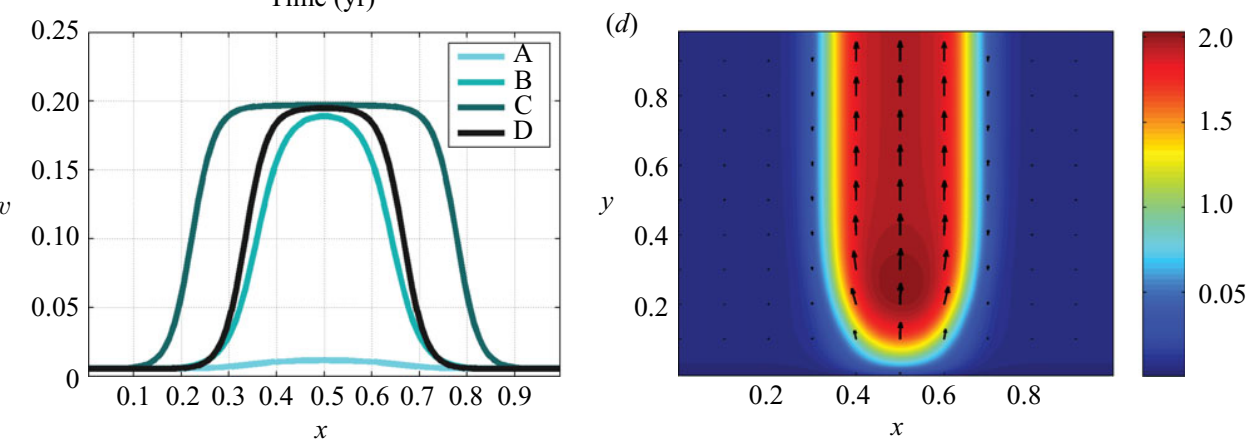

FIGURE 6. Diagnostics for the solution forced with a large magnitude mass source, $M=150 \mathrm{~m} \mathrm{yr}^{-1}$, as in figure 5. Note migration of the margins in panel $(c)$; initially outwards (from snapshot B to C) and then back inwards to a steady width (from snapshot C to D).

the upstream boundary. The driving stresses then reach a critical value and hence trigger a jump to a stream-like solution downstream from the source. However, the mass source is too weak to sustain the mass flux carried out of the domain by the stream-like solution. As a result, the ice-stream margins converge towards each other, until a collapse back to a no-stream solution occurs. The oscillation can be thought of as being between the no-stream and ice-stream steady solutions described earlier (§4.2.1 and §4.2.2). DeGiuli \& Schoof (2008) also found different oscillatory and other dynamical regimes, in a different model and due to seemingly different physical mechanism. Similarly, Schoof (2004a) found surge behaviour due to a multivalued relation between the ice flow and driving stress.

\section{Discussion}

The stable ice-stream-like solution presented in $\S 4.2 .2$ is possible because the triplevalued sliding law (4.1) allows a stable regime of fast flow to coexist with a stable regime of slower flow (figure 4). This, of course, critically depends on the speculative assumption that the longitudinal viscous stresses are not important away from the shear margin, as already pointed out above. Proceeding in spite of this uncertainty, consider the physical mechanism of the transition from a slow to a rapid stream-like flow seen as function of time ( $\S 4.2 .2$ and $\S 4.2 .3)$, which is also the surge mechanism of Hutter (1982a), Fowler (1987b) and Fowler \& Johnson (1996). The initially slow flow is accelerated by the driving stress due to the surface slopes generated by the mass source. The flow is stable at first because the bottom stress grows with the 

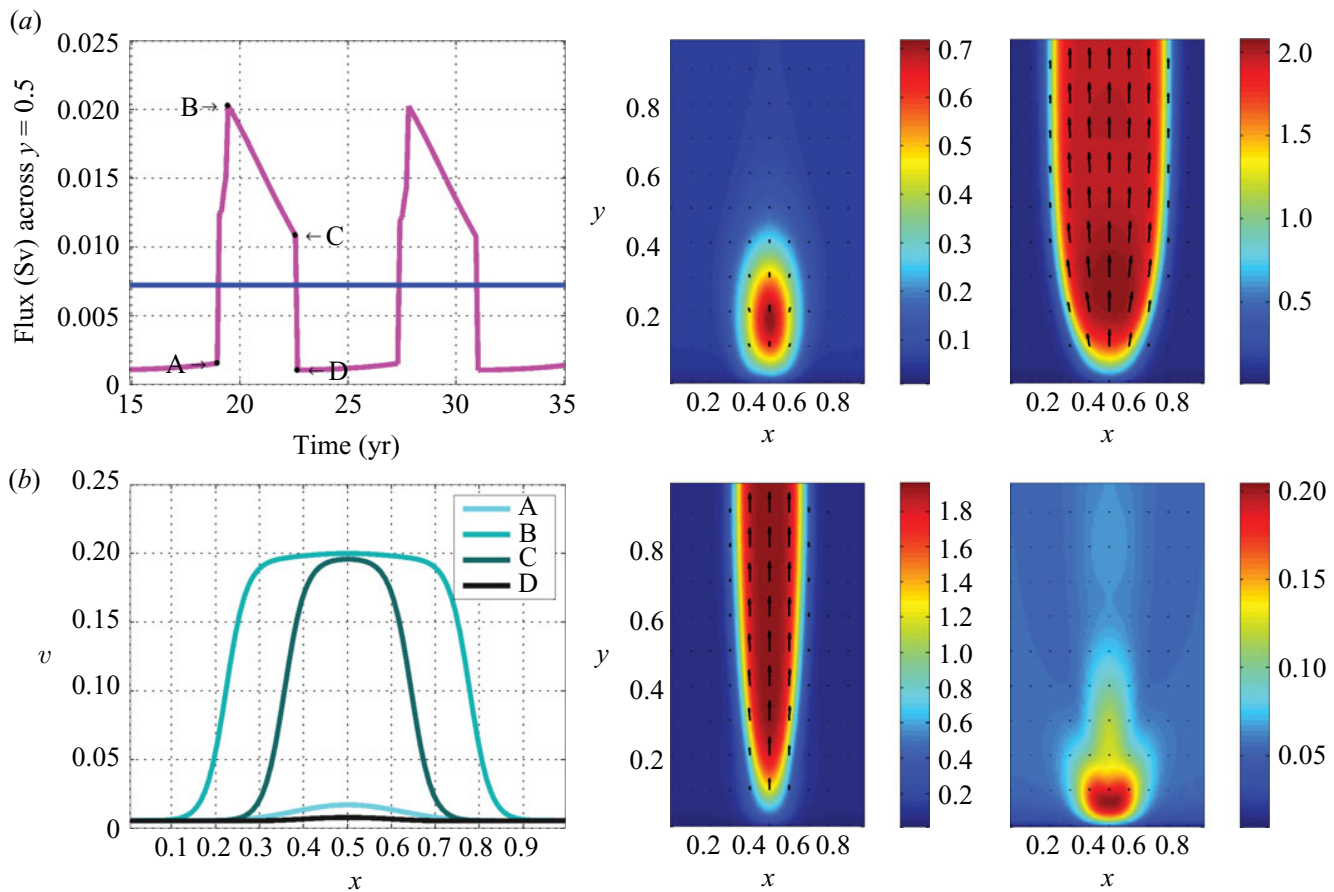

FIGURE 7. Diagnostics for the solution forced with an intermediate magnitude mass source, $M=100 \mathrm{~m} \mathrm{yr}^{-1}$, in which a relaxation oscillation develops. (a) The mass flux across $y=0.5$ (magenta) and the source mass influx $M$ (blue). $(b)$ The four snapshots of the cross-stream profiles of the downstream velocity, $v(x, y=0.5)$, at the times marked A, B, C, D in $(a)$. (A, B, C, D) The velocity field snapshots at time that correspond to the markers A, B, C, D in (a). One cycle period is $\sim 8.3 \mathrm{yr}$. Arrows show the velocity vectors and colours the flow speed (note the different colour scales).

sliding velocity (slow stable branch in figure 4). When the velocity grows larger than $v_{c_{1}}$ (figure 4), the bottom stress response becomes opposite which results in a flow instability (unstable branch in figure 4). This leads to a rapid growth in the downstream speed until the velocity reaches the stable fast branch beyond $v_{c_{2}}$. At that point the flow regains stability in the fast, ice-stream-like mode.

Figure 8 shows the corresponding spatial structure through an ice stream, of the downstream velocity $v$ and the bottom stress component $\tau_{y}^{b}$. The stress inside and outside of the ice stream, away from the shear margins, is similar (roughly equal to the driving stress $\tau_{d}$ ), while the velocity within the ice stream is larger than outside. This is a reflection of the triple-valued sliding law, (4.1). The behaviour of the bottom stress in the shear margins is quite complex. It first increases as one progresses from the slow flow region towards the stream itself, and then sharply decreases before increasing again to its value within the ice stream away from the shear margin. Within the shear margin, the velocity is in the linearly unstable range $\left(v_{c_{1}}<v<v_{c_{2}}\right)$ indicated in figure 4.

Consider the implications to the width of ice streams. An ice stream starts forming when the downstream velocity increases beyond the threshold $v_{c_{1}}$ in figure 4 , and the maximum stream velocity then increases rapidly until it settles on a value close to $v_{+}$ with a corresponding bottom shear stress, $\tau_{b} \simeq \tau_{d}$, similar to that at the region outside of the ice stream, where $v=v_{-}$. At steady state, given the integrated mass source 


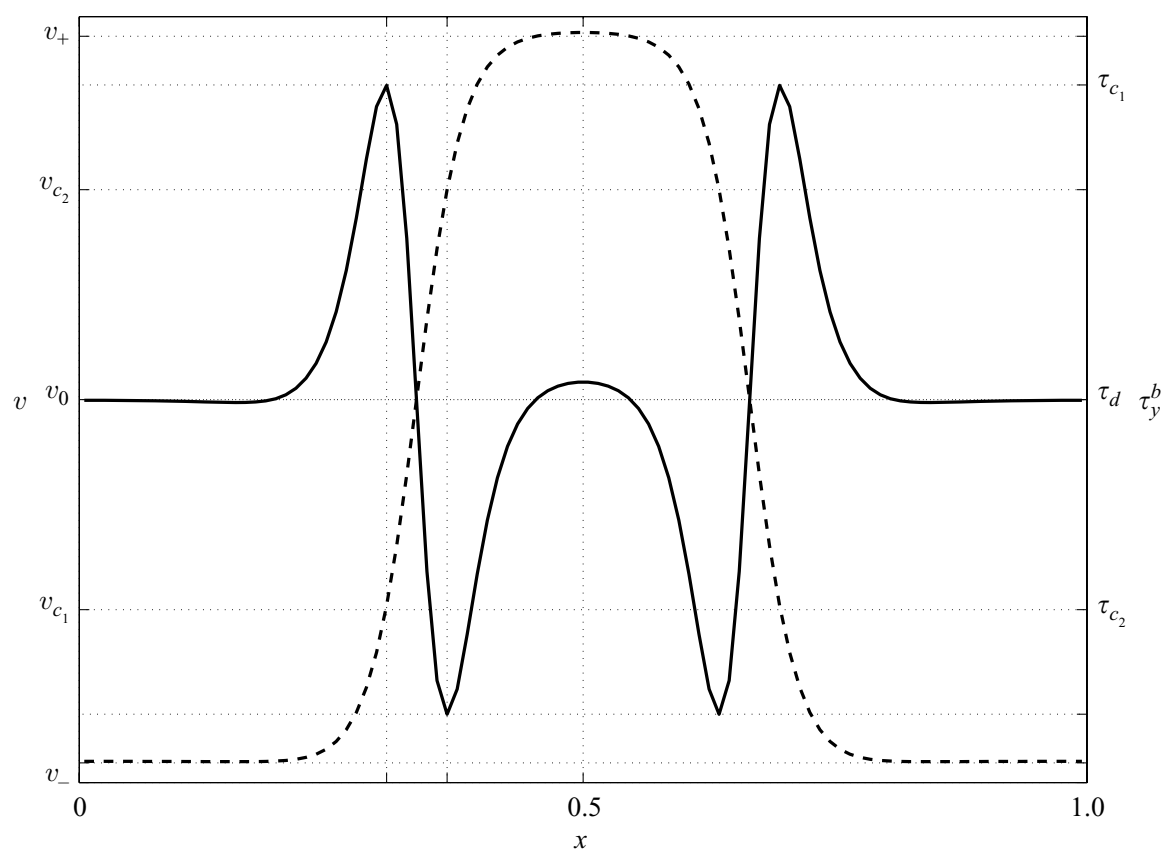

FIGURE 8. A steady state cross-section of the downstream speed $v(x, y=0.5)$ (dash), the downstream bottom stress component $\tau_{y}^{b}(x, y=0.5)$ (line), for an ice-stream-like solution $\left(\S 4.2 .2, M_{0}=150 \mathrm{~m} \mathrm{yr}^{-1}\right)$. Note that the velocity within the shear margin is in the linearly unstable range $\left(v_{c_{1}}<v<v_{c_{2}}\right)$ indicated in figure 4 .

$\bar{M} \equiv \int \mathrm{d} x \mathrm{~d} y M$, the expected velocity of $v_{+}$and the thickness of the ice $H$, one can derive the stream width needed to carry the prescribed mass source $W \sim \bar{M} /\left(v_{+} H\right)$. This argument is very qualitative, of course, as the driving stress itself is not constant and dynamically adjusts due to the mass transport which affects the surface slopes. The important message is, however, that in our model there is no intrinsic stream width set by the equations, and that the ice-stream steady width may vary with the mass source amplitude $M_{0}$ and spatial structure parameters $\sigma_{x}, \sigma_{y}$, assuming a fixed thickness and velocity. This is a falsifiable prediction of the model, and its validity would need to be further studied.

The numerical simulations of the two-dimensional ice streams (§4) showed that both the evolution to a steady ice-stream and the relaxation oscillations involve migration of the shear margins that leads to a widening or narrowing of the ice stream. These shear margin movements can be shown to be related to the driving stress due to the ice surface gradients, as described in $\S 3.2$ and in particular by (3.14) and (3.16).

The non-monotonous friction law was motivated above by the spatial structure of the ice stream, but may also be justified by a heuristic (and speculative) mechanism based on the reorganization of the hydraulic system under the ice at different flow regimes, following Kamb et al. (1985), Kamb (1987), Fowler (1987a,b) and the related references discussed in the introduction. At low sliding velocities, water production by basal frictional heating is low, and therefore the bed lubrication is ineffective, the bottom stress continues to grow as the sliding speed increases and melt water is possibly efficiently drained. As the sliding velocity increases, the excess of melt water and the poor drainage result in higher water pressure. This leads to efficient 
sliding and basal stresses that decrease with the sliding velocity. Eventually, when the sliding speed is even larger, a second reorganization of the hydraulic system occurs, leading to high-flow low-pressure channels which efficiently drain the subglacial melt water and therefore increase the bottom traction and stabilize the ice flow. Should this scenario be relevant to observed ice streams, such a transition between different subglacial drainage systems may be expected to occur along a section across an ice stream, although we are not aware of sufficiently detailed related observations.

\section{Conclusions}

We showed here that a triple-valued sliding law may be heuristically motivated by the transverse spatial structure of an ice stream. Within this triple-valued sliding law the basal stresses first increase with the sliding velocity, then decrease, and then increase again. We then demonstrated that such a sliding law can lead to some interesting stream-like patterns and time-oscillatory solutions.

Specifically, we find a spontaneous generation of rapid stream-like solutions within a slow ice-sheet flow, separated by narrow internal boundary layers (shear margins). These results were found using a combination of a detailed analysis of a simple one-dimensional transverse cross-section model and detailed numerical simulations of models in both horizontal directions, including explicit momentum equations and driven by a time independent mass source.

The sliding law used here is qualitatively similar to the one developed by Fowler (1987b), Fowler \& Johnson (1995), Fowler \& Johnson (1996) and Fowler \& Schiavi (1998) to explain the relaxation oscillation behaviour of ice surges. Fowler \& Johnson (1996) had further suggested that the same sliding law can also account for the spontaneous breakup of uniform ice flow and the formation of ice streams.

Several new elements have been introduced in this paper as an extension to these previous studies. First, we focused on the spatial structure implications of the multivalued sliding law, and analysed for the first time the detailed dynamical balance within the different regimes around the stream solution. Second, we showed that changing a single physical parameter, the mass source magnitude, leads to qualitative flow changes, from a slow creeping flow to a relaxation oscillation of the stream pattern ('ice-sheet surge' in the terminology of Fowler \& Johnson 1996), and to steady ice-stream-like solution. These flow regimes, similar to those seen by Fowler \& Johnson (1996), suggest that ice streams may in some sense be considered continuous surges as originally postulated by Weertman (1964). In particular, we showed that regions of the domain in which the flow is on the slow stable branch of the sliding law, can coexist with other regions in which the flow is on the faster stable branch, separated by shear margins. Third, we note that the triple-valued sliding law is motivated by the spatial structure of a stream-like solution, regardless of the physics used to justify the sliding law. We further showed that the adjustment of the ice-stream margins to changes in the driving stress may be described by a specific form of the Ginzburg-Landau equation. Finally, our model explicitly includes twodimensional momentum equations and longitudinal shear stresses, both not included in related past work on the development of ice stream and ice-sheet surges due to a multivalued sliding law. While we have attempted to provide a heuristic physical justification for the triple-valued sliding law in terms of subglacial hydrology, we did not develop a detailed physical model justifying this sliding law. 
The solutions and analysis we present do not indicate a scale-selection mechanism for the width of ice streams. Rather, they imply that the width scale is determined by the mass source distribution and intensity. This, of course, may simply be due to the many idealizations used here, but it is interesting to keep in mind the possibility raised here that ice-stream width is not determined by the flow dynamics.

Our model assumed a plug flow and did not include more realistic non-Newtonian rheology and thermoviscous effects. The ice-stream-like solutions found here do not have the complex spatial structure observed in nature. We also do not see a spatiotemporal variability such as the meandering of ice-stream paths as observed in Antarctica. It would be interesting to see whether the introduction of shear thinning, thermoviscous effects and multiple mass sources, in conjunction with the triple-valued sliding law, could account for this more complex spatiotemporal ice-stream variability.

We thank Christian Schoof, Richard Hindmarsh and an anonymous reviewer for providing very helpful, insightful, constructive and detailed reviews. We thank Christian Schoof also for pointing out a that the stability analysis for $R e=0$ is a singular perturbation problem and for proposing that we look into the shear margin dynamics. Thanks also to Jim Rice, Rick O’Connell, Shreyas Mandre and Ehud Meron for helpful discussions, and Chris Walker and the FAS computing team for their help. This work was supported by the McDonnell Foundation, and by the NSF paleoclimate programme grant ATM-0455470. E. Tziperman thanks the Weizmann Institute for its hospitality during parts of this work.

\section{Appendix A. Homogeneous analytic solutions for testing the numerical scheme}

Here we present two steady state analytical solutions of the two-dimensional model with the triple-valued sliding law, (3.4), that are used for comparison with the numerical simulation. The first is independent of the space coordinate $y$, with periodic along-flow boundary conditions. The second solution is $x$-independent with an open downstream boundary.

\section{A.1. Solution independent of $y$}

This solution is based on the one-dimensional analytic solution developed in $\S 3$. Assuming that in steady state $u=0, h=1$ and that $v$ is independent of $y$, then (2.1)-(2.3) reduce to the simpler set of equations (3.1). A solution for $v$ is

$$
v(x)= \begin{cases}1+v \tanh \left(r\left(x-x_{0}\right)\right) & \text { if } 0 \leqslant x \leqslant 1 / 2, \\ 1-v \tanh \left(r\left(x-x_{1}\right)\right) & \text { if } 1 / 2<x \leqslant 1,\end{cases}
$$

where $x_{0}<x_{1}$.

\section{A.2. Solution independent of $x$}

Assume a steady state with $u=0, h=1$ and that $v$ is independent of $x$. Equations (2.1)-(2.3) then become

$$
\begin{gathered}
\tau_{x}^{b}=0 \\
4 \in v_{, y y}-\phi b_{, y}-\tau_{y}^{b}=0, \\
M_{s}=\frac{\psi}{\eta} v_{, y}
\end{gathered}
$$




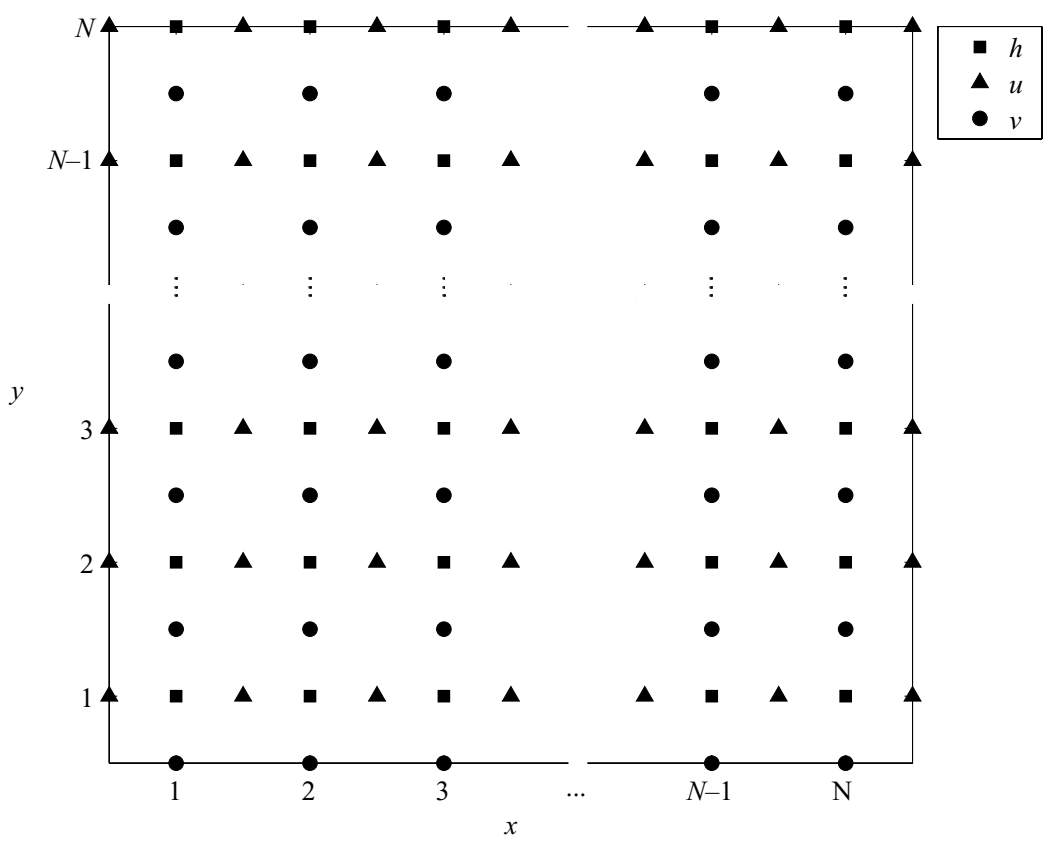

FiguRE 9. The staggered grid used for the finite difference solution of the two-dimensional flow. The $h$ and $v$ grids (squares and circles, respectively) are $N \times N$ and the $u$ grid (triangles) is $N \times N+1$, where $N=100$.

where $M_{s}$ represents a steady state mass source. The first equation is trivially satisfied as $u=0$. Following similar steps to those in $\S 3$, the solution for the second one is

$$
v(y)=1+v \tanh \left(\tilde{r}\left(y-y_{0}\right)\right),
$$

where , $\tilde{r}=\sqrt{(1 / 4 m)\left(v^{2} / 2\right)}$, and where

$$
y_{0}=\frac{1}{\tilde{r}} \tanh ^{-1}\left(v^{-1}\right)
$$

satisfies the boundary condition $v(y=0)=0 . v(y)$ can now be used in the third equation to obtain $M_{s}(y)$,

$$
M_{s}(y)=\frac{\psi}{\eta} \nu \tilde{r}\left(1-\tanh ^{2}\left(\tilde{r}\left(y-y_{0}\right)\right)\right) .
$$

\section{Appendix B. Numerical scheme}

The dimensional form of the two-dimensional model equations (2.1)-(2.3) are discretized on to the staggered grid shown in figure 9 (Rommelaere \& Ritz 1996). The diagnostic and nonlinear momentum equations are iteratively solved simultaneously. The time-dependent mass balance equation is integrated using a time-stepping approach. 


\section{B.1. Momentum balance}

The discretized form of the dimensional form of (2.1) is

$$
\begin{aligned}
0= & \frac{2}{\Delta x}\left[(\mu h)_{i, j}\left(2 \frac{u_{i+\frac{1}{2}, j}-u_{i-\frac{1}{2}, j}}{\Delta x}+\frac{v_{i, j+\frac{1}{2}}-v_{i, j-\frac{1}{2}}}{\Delta y}\right)\right. \\
& \left.-(\mu h)_{i-1, j}\left(2 \frac{u_{i-\frac{1}{2}, j}-u_{i-\frac{3}{2}, j}}{\Delta x}+\frac{v_{i-1, j+\frac{1}{2}}-v_{i-1, j-\frac{1}{2}}}{\Delta y}\right)\right] \\
& +\frac{1}{\Delta y}\left[\langle\mu h\rangle_{i, j+1}\left(\frac{u_{i-\frac{1}{2}, j+1}-u_{i-\frac{1}{2}, j}}{\Delta y}+\frac{v_{i, j+\frac{1}{2}}-v_{i-1, j+\frac{1}{2}}}{\Delta x}\right)\right. \\
& \left.-\langle\mu h\rangle_{i, j}\left(\frac{u_{i-\frac{1}{2}, j}-u_{i-\frac{1}{2}, j-1}}{\Delta y}+\frac{v_{i, j-\frac{1}{2}}-v_{i-1, j-\frac{1}{2}}}{\Delta x}\right)\right] \\
& -\frac{\tau_{0}}{v_{0} \vartheta_{u ; i, j}}\left(\left(\vartheta_{u ; i, j}-1\right)^{3}+a\left(\vartheta_{u ; i, j}-1\right)+1\right) \tanh \left(\beta \vartheta_{u ; i, j}\right) u_{i-\frac{1}{2}, j} \\
& -\frac{\rho g}{2 \Delta x}\left[\left(h_{i, j}^{2}-h_{i-1, j}^{2}\right)+\left(h_{i, j}+h_{i-1, j}\right)\left(z_{b ; i, j}-z_{b ; i-1, j}\right)\right],
\end{aligned}
$$

where $i$ and $j$ are the indices of the $x$ and $y$ coordinates respectively, $\Delta x$ and $\Delta y$ are the grid intervals and

$$
\begin{aligned}
\vartheta_{u ; i, j}^{n} & =\frac{1}{v_{0}} \sqrt{\left(u_{i-\frac{1}{2}, j}^{n-1}\right)^{2}+\frac{1}{16}\left(v_{i, j-\frac{1}{2}}^{n-1}+v_{i, j+\frac{1}{2}}^{n-1}+v_{i-1, j-\frac{1}{2}}^{n-1}+v_{i-1, j+\frac{1}{2}}^{n-1}\right)^{2},} \\
(\mu h)_{i, j} & \equiv \mu_{i, j} h_{i, j}, \\
\langle\mu h\rangle_{i, j} & \equiv \frac{1}{4}\left[(\mu h)_{i, j}+(\mu h)_{i-1, j}+(\mu h)_{i-1, j-1}+(\mu h)_{i, j-1}\right],
\end{aligned}
$$

where a superscript marks the time step index, unless mentioned otherwise (all variables whose time index is not specified are at time step $n$ ).

The discretized form of the (2.2) is identical to the above under permutation of $x \leftrightarrow y, u \leftrightarrow v$ and $i \leftrightarrow j$. Ordering the components $u_{i, j}, v_{i, j}$ of the time step $n$ in a single column vector $\boldsymbol{v}$, we get the system,

$$
M_{v} v=B_{v}
$$

where $\boldsymbol{M}_{\boldsymbol{v}}$ is a coefficient matrix and $\boldsymbol{B}_{\boldsymbol{v}}$ is a coefficient vector. To solve this system we take advantage of the sparsity of $\boldsymbol{M}_{\boldsymbol{v}}$, and preform this computation using Intel Fortran parallel sparse direct solver, PARDISO. Because (2.1) and (2.2) are nonlinear, the velocity field $\boldsymbol{v}$ has to be determined in an iterative fashion for $\boldsymbol{v}^{*}$, namely,

$$
\boldsymbol{M}_{v}\left(\boldsymbol{v}^{l}\right) \boldsymbol{v}^{*}=\boldsymbol{B}_{\boldsymbol{v}}
$$

where $l$ is the iteration step, $\boldsymbol{v}^{l=0}=\boldsymbol{v}^{n}$, and we let

$$
\boldsymbol{v}^{l+1}=\boldsymbol{v}^{*} \text {. }
$$

This is a Picard iteration (Rommelaere \& Ritz 1996). However, the fact that the value of $v$ and $u$ may vary two to three orders of magnitude over the ice-sheet domain, puts a high demand on the convergence scheme. To avoid divergence and optimize the convergence we apply a correction based on the subspace method of Hindmarsh \& Payne (1996). The correction vector of the Picard iteration $l$, is defined as $\boldsymbol{c}^{l} \equiv \boldsymbol{v}^{*}-\boldsymbol{v}^{l}$, while the error vector is defined as $\boldsymbol{e}^{l} \equiv \boldsymbol{v}^{l+1}-\boldsymbol{v}^{l}$. Assuming the decay is on straight line in the correction space, the Picard correction vector and the error vector are 
related by

$$
\boldsymbol{e}^{l}=\alpha c^{l}
$$

where

$$
\alpha=\frac{\left\|c^{l-1}\right\|_{2}}{\left\|c^{l}-c^{l-1}\right\|_{2}},
$$

and where $\|\cdot\|_{2}$, is the $L_{2}$ norm (Hindmarsh \& Payne 1996). The corrected velocity vector is therefore,

$$
\boldsymbol{v}^{l+1}=\boldsymbol{v}^{l}+\alpha \boldsymbol{c}^{l}
$$

This subspace correction to the Picard iteration is performed whenever the angle between successive iterations,

$$
\theta=\arccos \left(\frac{\boldsymbol{c}^{l} \cdot \boldsymbol{c}^{l-1}}{\left\|\boldsymbol{c}^{l}\right\|_{2}\left\|\boldsymbol{c}^{l-1}\right\|_{2}}\right),
$$

is not more than $\pi / 18$ away from 0 or $\pi$. The iteration cycle ends once the convergence criterion

$$
\max _{i, j}\left\{\left|\frac{u_{i, j}^{n-1}-u_{i, j}^{n}}{\text { r.m.s. }}\right|,\left|\frac{v_{i, j}^{n-1}-v_{i, j}^{n}}{\text { r.m.s. }}\right|\right\} \leqslant 10^{-4},
$$

where r.m.s. $=\sqrt{\left(\sum_{i, j} u_{i, j}^{2}+\sum_{i, j} v_{i, j}^{2}\right) /(N(N+1))}$ is fulfilled.

\section{B.2. Mass balance}

Using semi-implicit discretization we have,

$$
\begin{aligned}
\frac{h_{i, j}^{n+1}-h_{i, j}^{n}}{\Delta t}= & M_{i, j}-\frac{1}{\Delta x}\left(u_{i+\frac{1}{2}, j}^{n} \frac{h_{i+1, j}^{n+1}+h_{i, j}^{n+1}}{2}-u_{i-\frac{1}{2}, j}^{n} \frac{h_{i, j}^{n+1}+h_{i-1, j}^{n+1}}{2}\right) \\
& -\frac{1}{\Delta y}\left(v_{i, j+\frac{1}{2}}^{n} \frac{h_{i, j+1}^{n+1}+h_{i, j}^{n+1}}{2}-v_{i, j-\frac{1}{2}}^{n} \frac{h_{i, j}^{n+1}+h_{i, j-1}^{n+1}}{2}\right) .
\end{aligned}
$$

Arranging the thickness field $h_{i, j}^{n+1}$ in a column vector $\boldsymbol{h}$ we get a set of linear equations,

$$
\boldsymbol{M}_{\boldsymbol{h}} \boldsymbol{h}^{n+1}=\boldsymbol{B}_{\boldsymbol{h}}
$$

where $\boldsymbol{M}_{\boldsymbol{h}}$ is a sparse coefficient matrix and $\boldsymbol{B}_{\boldsymbol{h}}$ is a coefficients vector. This system is also solved with the parallel direct sparse solver PARDISO with the time step $\Delta t$ varying according to the number of iterations it takes the diagnostic system to converge. If the number of iterations is greater than 20, we set $\Delta t^{n+1}=\Delta t^{n} / 10$, otherwise, $\Delta t^{n+1}=2 \Delta t^{n}$, as long as $\Delta t_{\text {min }}<\Delta t^{n+1}<\Delta t_{\text {max }}$, where $\Delta t_{\text {min }}=1 \mathrm{~min}$ and $\Delta t_{\max }=12 \mathrm{~h}$.

\section{B.3. Boundary conditions}

The finite difference formulation of the upstream closed boundary at $y=0$ (4.2) and at the two side boundaries $x=0,1(2.6)$ are standard, but the open boundary condition at $y=1$ does require some further explanation.

\section{B.3.1. Down-stream boundary at $y=1$}

The downstream boundary conditions are based on the outflow condition suggested by Papanastasiou et al. (1992). The solution becomes numerically unstable as the 
boundary layer front approaches the outflow boundary. We overcome this problem by combining this outflow boundary condition with the additional condition, (4.3). The downstream boundary is set up at $u$ and $h$ grid points $j=N$, and we next write the near-boundary equations for $u$ and $h$ at the grid points $(i, N)$ and for $v$ at the near-boundary $v$-grid points at $(i, N-1 / 2)$. This is done using quadratic extrapolation in $y$ and an upwind difference scheme near the boundary.

The resulting discretized form of the momentum equation (2.1) at the boundary is therefore,

$$
\begin{aligned}
0= & \frac{2}{\Delta x}\left[(\mu h)_{i, j}\left(2 \frac{u_{i+\frac{1}{2}, j}-u_{i-\frac{1}{2}, j}}{\Delta x}\right)-(\mu h)_{i-1, j}\left(2 \frac{u_{i-\frac{1}{2}, j}-u_{i-\frac{3}{2}, j}}{\Delta x}\right)\right] \\
& +\left(\frac{(\mu h)_{i, j}-(\mu h)_{i, j-1}+(\mu h)_{i-1, j}-(\mu h)_{i-1, j-1}}{2 \Delta y}\right) \\
& \cdot\left(\frac{3 u_{i-\frac{1}{2}, j}-4 u_{i-\frac{1}{2}, j-1}+u_{i-\frac{1}{2}, j-2}}{2 \Delta y}+\frac{v_{i, j-\frac{1}{2}}-v_{i-1, j-\frac{1}{2}}}{\Delta x}\right) \\
& +\left(\frac{(\mu h)_{i, j}+(\mu h)_{i-1, j}}{2}\right)\left(\frac{u_{i-\frac{1}{2}, j}-2 u_{i-\frac{1}{2}, j-1}+u_{i-\frac{1}{2}, j-2}}{\Delta y^{2}}\right) \\
& -\frac{\tau_{0}}{v_{0} \vartheta_{u ; i, j}}\left(\left(\vartheta_{u ; i, j}-1\right)^{3}+a\left(\vartheta_{u ; i, j}-1\right)+1\right) \tanh \left(\beta \vartheta_{u ; i, j}\right) u_{i-\frac{1}{2}, j} \\
& -\frac{\rho g}{2 \Delta x}\left[\left(h_{i, j}^{2}-h_{i-1, j}^{2}\right)+\left(h_{i, j}+h_{i-1, j}\right)\left(z_{b ; i, j}-z_{b ; i-1, j}\right)\right],
\end{aligned}
$$

where $\vartheta_{u ; i, j}^{n}$ is given by (B 1).

The discretized form of the along-flow momentum equation (2.2) at the grid point $(i, N-1 / 2)$ is,

$$
\begin{aligned}
0= & \frac{1}{\Delta x}\left[\langle\mu h\rangle_{i+1, j}\left(\frac{u_{i+\frac{1}{2}, j}-u_{i+\frac{1}{2}, j-1}}{\Delta y}+\frac{v_{i+1, j-\frac{1}{2}}-v_{i, j-\frac{1}{2}}}{\Delta x}\right)\right. \\
& \left.-\langle\mu h\rangle_{i, j}\left(\frac{u_{i-\frac{1}{2}, j}-u_{i-\frac{1}{2}, j-1}}{\Delta y}+\frac{v_{i, j-\frac{1}{2}}-v_{i-1, j-\frac{1}{2}}}{\Delta x}\right)\right] \\
& +\frac{2}{\Delta y}\left[(\mu h)_{i, j}\left(\frac{u_{i+\frac{1}{2}, j}-u_{i-\frac{1}{2}, j}}{\Delta x}\right)-(\mu h)_{i, j-1}\right. \\
& \left.\times\left(\frac{u_{i+\frac{1}{2}, j-1}-u_{i-\frac{1}{2}, j-1}}{\Delta x}+2 \frac{v_{i, j-\frac{1}{2}}-v_{i, j-\frac{3}{2}}}{\Delta y}\right)\right] \\
& -\frac{\tau_{0}}{v_{0} \vartheta_{v i, j}}\left(\left(\vartheta_{v ; i, j}-1\right)^{3}+a\left(\vartheta_{v ; i, j}-1\right)+1\right) \tanh \left(\beta \vartheta_{v ; i, j}\right) v_{i, j-\frac{1}{2}} \\
& -\frac{\rho g}{2 \Delta y}\left[\left(h_{i, j}^{2}-h_{i, j-1}^{2}\right)+\left(h_{i, j}+h_{i, j-1}\right)\left(z_{b ; i, j}-z_{b ; i, j-1}\right)\right],
\end{aligned}
$$

where $j=N$.

Similarly, the discretized form of (2.3) is,

$$
\begin{aligned}
\frac{h_{i, j}^{n+1}-h_{i, j}^{n}}{\Delta t}= & M_{i, j}-\frac{1}{\Delta x}\left(u_{i+\frac{1}{2}, j}^{n} \frac{h_{i+1, j}^{n+1}+h_{i, j}^{n+1}}{2}-u_{i-\frac{1}{2}, j}^{n} \frac{h_{i, j}^{n+1}+h_{i-1, j}^{n+1}}{2}\right) \\
& -\frac{1}{\Delta y} v_{i, N}\left(h_{i, j}^{n+1}-h_{i, j-1}^{n+1}\right),
\end{aligned}
$$

where $j=N$. 


\section{REFERENCES}

Anandakrishnan, S. \& Alley, R. B. 1997 Stagnation of Ice Stream C, West Antarctica by water piracy. Geophys. Res. Lett. 24, 265-268.

Balmforth, N. J., Craster, R. V. \& Toniolo, C. 2003 Interfacial instability in non-Newtonian fluid layers. Phys. Fluids 15 (11), 3370-3384.

Bindschadler, R. A., King, M. A., Alley, R. B., Anandakrishnan, S. \& Padman, L. 2003 Tidally controlled stick-slip discharge of a West Antarctic ice stream. Science 301 (5636), 10871089.

Boulton, G. S. \& Hindmarsh, R. C. A. 1987 Sediment deformation beneath glaciers - rheology and geological consequences. J. Geophys. Res. 92 (B9), 9059-9082.

Boulton, G. S., Lunn, R., Vidstrand, P. \& Zatsepin, S. 2007 a Subglacial drainage by groundwaterchannel coupling, and the origin of esker systems. Part 1. Glaciological observations. Quat. Sci. Rev. 26 (7-8), 1067-1090.

Boulton, G. S., Lunn, R., Vidstrand, P. \& Zatsepin, S. 2007b Subglacial drainage by groundwaterchannel coupling, and the origin of esker systems. Part II. Theory and simulation of a modern system. Quat. Sci. Rev. 26 (7-8), 1091-1105.

Clark, P. U. \& Walder, J. S. 1994 Subglacial drainage, eskers, and deforming beds beneath the Laurentide and Eurasian ice sheets. Geol. Soc. Am. Bull. 106 (2), 304-314.

DeGiuli, E. \& Schoof, C. 2008 Hysteresis and chaos in ice stream behaviour. In Geophysical Research Abstracts, pp. 10, EGU2008-A-00854. EGU.

Fountain, A. G. 1994 Borehole water-level variations and implications for the subglacial hydraulics of South Cascade Glacier, Washington State, USA. J. Glaciol. 40 (135), 293-304.

FowleR, A. C. 1986 A sliding law for glaciers of constant viscosity in the presence of subglacial cavitation. Proc. R. Soc. Lond. Ser. A - Math. Phys. Engng Sci. 407 (1832), 147-170.

Fowler, A. C. $1987 a$ Sliding with cavity formation. J. Glaciol. 33 (115), 255-267.

Fowler, A. C. 1987b A theory of glacier surges. J. Geophys. Res. 92 (B9), 9111-9120.

Fowler, A. C. 1989 A mathematical analysis of glacier surges. SIAM J. Appl. Math. 49 (1), 246263.

Fowler, A. C. \& Johnson, C. 1995 Hydraulic run-away - a mechanism for thermally regulated surges of ice sheets. J. Glaciol. 41 (139), 554-561.

Fowler, A. C. \& Johnson, C. 1996 Ice sheet surging and ice stream formation. Ann. Glaciol. 23, $68-73$.

Fowler, A. C. \& Schiavi, E. 1998 A theory of ice-sheet surges. J. Glaciol. 44 (146), 104-118.

Gagliardini, O., Cohen, D., Raback, P. \& Zwinger, T. 2007 Finite-element modelling of subglacial cavities and related friction law. J. Geophys. Res. 112 (F2), F02027.1-F02027.13.

Greenberg, J. M. \& Shyong, W. 1990 Surging glacial flows. IMA J. Appl. Math. 45 (3), 195-223.

Hagberg, A. \& Meron, E. 1993 Domain-walls in nonequilibrium systems and the emergence of persistent patterns. Phys. Rev. E 48 (2), 705-708.

Hagberg, A. \& Meron, E. 1994 Pattern-formation in nongradient reaction-diffusion systems - the effects of front bifurcations. Nonlinearity 7 (3), 805-835.

Hindmarsh, R. C. A. 2006 Stress gradient damping of thermoviscous ice flow instabilities. J. Geophys. Res. 111 (B12409), 1-8, doi:10.1029/2005JB004019.

Hindmarsh, R. C. A. \& Payne, A. J. 1996 Time-step limits for stable solutions of the ice-sheet equation. Ann. Glaciol. 23, 74-85.

Hutter, K. $1982 a$ Dynamics of glaciers and large ice masses. Annu. Rev. Fluid Mech. 14, 87-130.

Hutter, K. $1982 b$ Glacier flow. Am. Scientist 70 (1), 26-34.

IKEN, A. 1981 The effect of the subglacial water pressure on the sliding velocity of a glacier in an idealized numerical model. J. Glaciol. 27, 407-421.

Joughin, I., MacAyeal, D. R. \& TulaczyK, S. 2004 Basal shear stress of the Ross ice streams from control method inversions. J. Geophys. Res. 109 (B09405), 1-20, doi:10.1029/2003JB002960.

Kамв, B. 1970 Sliding motion of glaciers - theory and observation. Rev. Geophys. Space Phys. 8 (4), 673-728.

Kамв, B. 1987 Glacier surge mechanism based on linked cavity configuration of the basal water conduit system. J. Geophys. Res. 92 (B9), 9083-9100. 
Kamb, B. \& Engelhardt, H. F. 1991 Antarctic ice stream B: conditions controlling its motions and interactions with the climate system. Intl Assoc. Sci. Hydrol. Publ. 208, 145-154.

Kamb, B., Raymond, C. F., Harrison, W. D., Engelhardt, H., Echelmeyer, K. A., Humphrey, N., Brugman, M. M. \& Pfeffer, T. 1985 Glacier surge mechanism - 1982-1983 surge of Variegated Glacier, Alaska. Science 227 (4686), 469-479.

Lliboutry, L. 1968 General theory of subglacial cavitation and sliding of temperate glaciers. J. Glaciol. 7 (49), 21-58.

Lliboutry, L. 1969 Contribution la thorie des ondes glaciaires. Can. J. Earth Sci. 6 (4), 943-953.

LLIBOUTRY, L. 1979 Local friction laws for glaciers: a critical review and new openings. J. Glaciol. 23 (89), 67-95.

LLIBOUtRY, L. 1987 Realistic, yet simple bottom boundary-conditions for glaciers and ice sheets. J. Geophys. Res. 92 (B9), 9101-9109.

MacAyeAL, D. R. 1989 Large-scale ice flow over a viscous basal sediment - theory and application to Ice Stream B, Antarctica. J. Geophys. Res. 94 (B4), 4071-4087.

MacAyeal, D. R., Bindschadler, R. A. \& Scambos, T. A. 1995 Basal friction of Ice Stream E, West Antarctica. J. Glaciol. 41, 247-262.

McMeeking, R. M. \& Johnson, R. E. 1986 On the mechanics of surging glaciers. J. Glaciol. 32 (110), 120-132.

NYE, J. F. 1969 A calculation on sliding of ice over a wavy surface using a Newtonian viscous approximation. Proc. R. Soc. Lond. Ser. A - Math. Phys. Sci. 311 (1506), 445-467.

NyE, J. F. 1970 Glacier sliding without cavitation in a linear viscous approximation. Proc. R. Soc. Lond. Ser. A - Math. Phys. Sci. 315 (1522), 381-403.

Papanastasiou, T. C., Malamataris, N. \& Ellwood, K. 1992 A new outflow boundary-condition. Intl J. Numer. Methods Fluids 14 (5), 587-608.

Price, S. F., Bindschadler, R. A., Hulbe, C. L. \& Blankenship, D. D. 2002 Force balance along an inland tributary and onset to Ice Stream D, West Antarctica. J. Glaciol. 48 (160), 20-30.

Raymond, C. F. 1987 How do glaciers surge - a review. J. Geophys. Res. 92 (B9), 9121-9134.

Raymond, C. F., Echelmeyer, K., Whillans, I. \& Doake, C. 2001 Ice stream shear margins. In The West Antarctic Ice Sheet - Behaviour and Environment, Antarctic Research Series, vol. 77, pp. 137-155. AGU.

Rempel, A. W. 2008 A theory for ice-till interactions and sediment entrainment beneath glaciers. J. Geophys. Res. 113 (F01013), 1-20, doi:10.1029/2007JF000870.

Retzlaff, R. \& Bentley, C. R. 1993 Timing of stagnation of Ice Stream-C, West Antarctica, from short-pulse radar studies of buried surface crevasses. J. Glaciol. 39 (133), 553-561.

Rommelaere, V. \& Ritz, C. 1996 A thermomechanical model of ice-shelf flow. Ann. Glaciol. 23, $13-20$.

Rothlisberger, H. 1972 Water pressure in intra- and subglacial channels. J. Glaciol. 11, 177-203.

SAYAG, R. \& TZIPERMAN, E. 2008 Spontaneous generation of pure ice streams via flow instability: role of longitudinal shear stresses and subglacial till. J. Geophys. Res. 113 (B12), B05411, $1-17$.

Schoof, C. 2004a Bed topography and surges in ice streams. Geophys. Res. Lett. 31 (6), L06401.

SCHOOF, C. $2004 b$ On the mechanics of ice-stream shear margins. J. Glaciol. 50 (169), 208-218.

SCHOOF, C. 2005 The effect of cavitation on glacier sliding. Proc. R. Soc. A - Math. Phys. Engng Sci. 461 (2055), 609-627.

Schoof, C. \& Rempel, A. 2008 Ice stream shear margin migration. In Geophysical Research Abstracts, pp. 10, EGU2008-A-11577. EGU.

StePHENSON, S. N. \& BindsChADLER, R. A. 1988 Observed velocity fluctuations on a major Antarctic ice stream. Nature 334, 695-697.

Stokes, C. R., Clark, C. D., Lian, O. B. \& TulaczyK, S. 2007 Ice stream sticky spots: a review of their identification and influence beneath contemporary and palaeo-ice streams. Earth-Sci. Rev. 81 (3-4), 217-249.

WALDER, J. S. 1982 Stability of sheet flow of water beneath temperate glaciers and implications for glacier surging. J. Glaciol. 28 (99), 273-293. 
Walder, J. S. \& Fowler, A. 1994 Channelized subglacial drainage over a deformable bed. J. Glaciol. 40 (134), 3-15.

Weertman, J. 1964 The theory of glacier sliding. J. Glaciol. 5, 287-303.

WeErtman, J. 1972 General theory of water flow at base of a glacier or ice sheet. Rev. Geophys. Space Phys. 10 (1), 287-333.

WeErtman, J. 1979 The unsolved general glacier sliding problem. J. Glaciol. 23, 97-115.

Whillans, I. M. \& VAN Der VeEn, C. J. 1997 The role of lateral drag in the dynamics of Ice Stream B, Antarctica. J. Glaciol. 43 (144), 231-237. 